\title{
HEILMAN, JAYMIE (2018). REBELIONES INCONCLUSAS. AYACUCHO ANTES DE SENDERO LUMINOSO
}

\author{
LIMA: LA SINIESTRA ENSAYOS
}

\section{Raúl César MARCELO DOROTEO}

\author{
Universidad Nacional Mayor de San Marcos
}

cesarraulmado@gmail.com

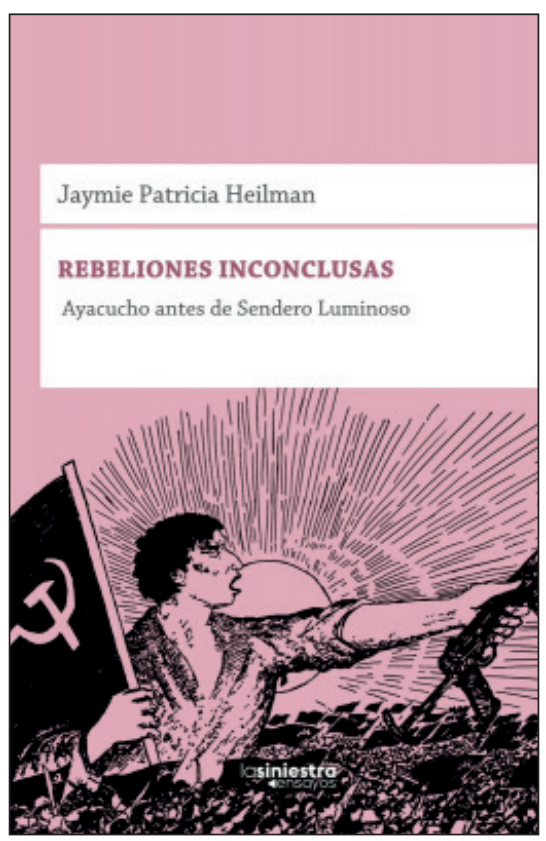

T

omando como un todo, los ochenta y cinco años de historia examinados en este libro sugieren que la guerra popular de Sendero Luminoso fue un periodo tanto de continuidad como de ruptura histórica. (Heilman, 2018, pág. 292)

El texto Rebeliones inconclusas, publicado por la editorial La Siniestra, se suma a los numerosos estudios publicados sobre la guerra interna que los/as peruanos/ as experimentamos durante las dos últimas décadas del siglo XX. Sin embargo, este texto se diferencia de los demás por el enfoque -a la vez local, histórico y antropológico- planteado al abordar el espinoso tema de la insurrección senderista.

Para explicar la insurrección senderista, Heilman ensaya una mirada retrospectiva de 85 años de historia local, regional y nacional de la sociedad peruana. A partir de ello, sostiene que"la lucha armada del PCP-SL fue una continuación de los esfuerzos 
y acciones políticas que se extienden a lo largo del siglo XX. [...] [y este partido] propuso un proyecto político diseñado para restructurar fundamentalmente el Estado-nación peruano y transformar las relaciones políticas, económicas y sociales dentro del país" (pág. 292). Por esta razón, el abordaje histórico resulta fundamental. En esta historia, los principales protagonistas son los campesinos de las comunidades ayacuchanas de Carhuanca (provincia de Cangallo) y Luricocha (provincia de Huanta). La acción política local de estos campesinos se desarrolló al unísono con las propuestas de organizaciones políticas de alcance nacional (comité Tawantinsuyo, partido aprista, Acción Popular, el Velasquismo y Sendero Luminoso). Consiguientemente, la autora decidió centrar su mirada analítica en la política e historia de las comunidades mencionadas, con el propósito de "conocer los triunfos, fracasos, odios y fidelidades políticas de individuos y familias especificas a lo largo del tiempo" (pág. 18).

La virtud de la narrativa histórico-local es que permite a Heilman situar la insurrección armada senderista en el tiempo y vincularla con lo que venía ocurriendo en las zonas rurales de la sociedad andina, donde se suscitaban conflictos -en especial, por tierras- entre notables locales y campesinos pobres, entre campesinos pobres y entre comunidades campesinas. Carhuanca no era ajena a esta realidad. En aquel escenario irrumpió Sendero Luminoso y muchos de sus integrantes eran hijos de campesinos indígenas. Con el objetivo de explicar esta historia, la autora acudió al archivo y a la memoria histórica de los comuneros. Para abordar esta última fuente, recurrió a la antropología: realizó trabajo de campo, recopilando los testimonios de las personas que se vieron obligadas a vivir distintas situaciones en las comunidades de Carhuanca y Luricocha. Un aspecto distintivo de esta investigación es que la autora polemiza con las perspectivas de sus informantes, a quienes no subestima.

Otro elemento valioso del texto es la manera en que está narrado: el contrapunteo. Esta técnica -de comparación y búsqueda de las diferencias entre protagonistas de la historia- le permite a Heilman precisar la heterogeneidad de las estructuras políticas, el comportamiento político de los campesinos, el actuar de las élites locales y, por último, la asimilación de las agendas de las organizaciones nacionales en las comunidades de Carhuanca y Luricocha. De esta forma, evidencia la pluralidad, la movilidad histórica y el cambio permanente en el mundo andino rural.

Los conceptos de raza y clase -que permiten a la autora definir las diferencias, las injusticias socio-económicas y su inmediato desenlace de violencia entre campesinos en distintos momentos de los 85 años narrados- están presentes a lo largo del texto. Su uso posibilita comprender la estructura socio-política de las comunidades de Carhuanca y Luricocha, distinguiendo la existencia en ambas de una élite política: los denominados notables, quienes basaban su poder en la tenencia de tierras, dinero y educación (prestigio). Este capital socio-culturaleconómico facilitaba a los potentados controlar la administración pública local, asumiendo los cargos de teniente gobernador, alcalde, juez de Paz y subprefecto. El ejercicio de estos cargos políticos viabilizaba que los potentados expandieran la tenencia de tierras y perpetraran abusos de distinta índole contra la población 
indígena monolingüe, lo cual ocurría en mayor medida en Carhuanca que en Luricocha.

Heilman sostiene que los campesinos indígenas siempre se habían organizado para combatir las injusticias perpetradas por los potentados locales y tinterillos. Al parecer, los atropellos iban a llegar a su fin con las reformas velasquistas, que pretendían democratizar los espacios rurales a partir del Estatuto de las Comunidades Campesinas, el cual amparaba la elección universal para elegir autoridades comunales; pero esto duró poco tiempo, puesto que hubo un cambio en el poder central. En consecuencia, los conflictos locales recrudecieron, hasta que apareció Sendero Luminoso. Esta organización política emprendió "acciones punitivas decisivas contra los mismos gamonales y autoridades cuyos abusos los carhuaquinos habían desafiado repetidamente y sin éxito" (pág. 298). Dichas acciones originaron que mucha gente carhuaquina se plegara voluntariamente a los senderistas, dado que se estaba aniquilando a la élite local abusiva. De ese modo, Heilman cuestiona la principal tesis de Carlos Iván Degregori -considerado el principal senderólogo-, quien sostuvo que el carácter de subyugados de los campesinos hizo que aceptaran sin cuestionamiento al nuevo patrón llamado Sendero Luminoso. En cambio, para Heilman la agenda de los carhuaquinos coincidía con el accionar de Sendero Luminoso.

Para la autora, el abandono o la ausencia del Estado en las zonas rurales, al menos en Carhuanca, posibilitó que muchos potentados perpetraran abusos contra los más vulnerables, los campesinos indígenas, negándoles la posibilidad de ocupar cargos administrativos, privándolos de educación, aprovechándose de su mano de obra de forma gratuita o arrebatándoles sus tierras mediante artimañas. El Estado peruano hacía caso omiso de estos problemas, a pesar de las quejas reiteradas de los campesinos pobres. Ese mismo abandono estatal permitió que Sendero Luminoso se organizara y expandiera en las zonas rurales mediante sus Escuelas Populares, dirigidas por jóvenes egresados de la Facultad de Educación de la Universidad Nacional de San Cristóbal de Huamanga (UNSCH). Mediante esta táctica, Sendero incorporó militantes campesinos y fue preparando el terreno para su lucha armada. En 1978, el Estado retiró la base policial de la zona oriental de la provincia de Cangallo, hecho que posibilitó que Sendero realizara proselitismo político y militar en dicha zona. Ante ello, las autoridades locales solicitaron el regreso de las fuerzas policiales al Gobierno central y al regional, pero ninguno respondió. De esta suerte, Sendero se extendió, detentando como base social al campesinado, y posteriormente puso en vilo al propio Estado peruano.

Otra contribución de la investigación de Heilman consiste en develar que el campesinado indígena de Carhuanca y Luricocha estuvo permeado por la agenda política de los partidos políticos (APRA, Acción Popular y Sendero Luminoso) y por las decisiones asumidas por las instituciones de rango nacional (estatales). Por ende, los campesinos no fueron meros espectadores de la historia local y nacional; por el contrario, sus acciones políticas cotidianas estuvieron imbricadas en el accionar y las decisiones de las organizaciones de alcance nacional. Tampoco asumieron pasivamente las agendas de estas organizaciones, 
sino que los campesinos de las distintas clases sociales las recrearon en función de sus intereses colectivos, particulares o privados. Por ejemplo, la acción política de los carhuaquinos "se manifestó en la participación en movimientos y partidos, incluyendo el PCP-SL" (pág. 293). Muchos campesinos carhuaquinos, al sumarse a las filas de Sendero, cobraron venganza, aniquilando a los potentados locales y tinterillos, lo cual generó una hecatombe en las zonas rurales ayacuchanas.

A medida que el conflicto avanzaba, la situación se tornaba más compleja para los mandos senderistas, los cuales empezaron reproducir los abusos y escarmientos que inicialmente habían castigado. Heilman sostiene que comenzaron ajusticiar a los campesinos pobres indígenas que se negaban a plegarse a su lucha armada. A esta circunstancia, añadiría la siguiente hipótesis: el accionar intransigente e intolerante de los mandos senderistas generó el rechazo y la repulsión de los familiares de las víctimas de tales acciones, quienes posteriormente conformaron el Comité de Autodefensa, el cual se convirtió luego en el principal artífice de la derrotar militar de la guerrilla senderista.

En conclusión, la sublevación senderista fue una más de aquellas rebeliones inconclusas, de esos proyectos abortados ya sea por la torpeza de sus dirigentes o por el accionar militar estratégico del Estado. Algo que devela el texto -aunque la autora no reflexiona sobre ello- es que el Estado acudió invariablemente al campesinado para derrotar las insurrecciones suscitadas en el interior del país, dejándolas así inconclusas. Finalmente, la autora plantea que el accionar guerrillero de Sendero Luminoso solo se podrá entender a la luz de la historia, en cuanto se pronuncien los actores y testigos de esta guerra que nos tocó vivir. Dicha historia debe ser escrita y discutida sin caer en juicios de valor ni apasionamientos por las víctimas, por Sendero o por las fuerza armadas y policiales. 